\title{
Potentially Avoidable Hospitalizations at Grand Yoff General Hospital, Senegal
}

\author{
Abdoul Aziz Ndiaye ${ }^{1,2}$, Alioune Badara Tall ${ }^{1}$, Ndeye Fatou Ngom-Gueye ${ }^{1}$, Ousseynou Ka ${ }^{1}$, Birahim Thiam ${ }^{1}$, \\ Amadou Barro Mbodj ${ }^{2}$, Cheikh Tacko Diop ${ }^{1}$, Awa Diop-B ${ }^{1}$, Lamine Gueye ${ }^{1} \&$ Anta Tal-Dia ${ }^{3}$ \\ ${ }^{1}$ Department of Community Health, Alioune Diop University, Bambey, Senegal \\ ${ }^{2}$ Military Health service Senegal, Senegal \\ ${ }^{3}$ Public Health Department, Cheikh Anta Diop University, Dakar, Senegal \\ Correspondence: Abdoul Aziz Ndiaye, Department of Community Health, UFR Health and Sustainable \\ Development, Alioune Diop University of Bambey, Box 30, Bambey, Senegal. E-mail: ndiaziz2000@yahoo.fr; \\ abdoulaziz.ndiaye@uadb.edu.sn
}

Received: July 12, 2017 Accepted: August 12, 2017 Online Published: September 6, 2017

doi:10.5539/gjhs.v9n10p137 URL: https://doi.org/10.5539/gjhs.v9n10p137

\begin{abstract}
Background: PAHs are necessary hospitalizations that could be prevented by appropriate primary care. They are mainly attributable to non-communicable diseases (NCDs), which are increasing, especially in developing countries. The objective of this research was to evaluate the epidemiological burden of the PAHs at Grand Yoff General Hospital.
\end{abstract}

Methodology: A cross-sectional study was carried out in 2015. The population consisted of all patients hospitalized from April to August 2015, except those who were admitted to surgery, maternity or neonatology departments. This was a comprehensive study; the cases were represented by patients admitted for diabetes, high blood pressure, pulmonary disease, chronic kidney disease or stroke.

Results: A total of 739 hospitalizations were recorded in the targeted services, including 110 cases of PAHs (14.88\%). Pulmonary disease was slightly more frequent (4.74\%), followed by diabetes $(4.08 \%)$, stroke (3.65\%), then chronic kidney disease (1.35\%) and high blood pressure (1.08\%). The average age of cases was $57 \pm 17.49$ years and $54.5 \%$ of patients were 60 years of age or older, the sex ratio was 0.96 , the married $68.2 \%$, and the widowed $20 \%$. About $34 \%$ of the patients were uneducated and $24 \%$ had just a primary school level. Only $8.2 \%$ were employed, while $43 \%$ were housewives and $23 \%$ were retired. $70 \%$ got a monthly income less than 100 USD. The median length of stay was 5 days. The level of awareness of the severity of the disease had improved significantly, from $37.3 \%$ at entry to $71.8 \%$ at the end of the stay $(\mathrm{p}<0.01)$. That was the same for the level of information about the means of preventing disease prevention, from $32.7 \%$ to $64.5 \%$ with a $p$ value $<0.01$.

A similar frequency of PAHs was reported in another study carried out in a regional hospital in northern Senegal $(15 \%)$ with a predominance of the elderly.

Conclusion: PAHs are a heavy burden at Grand Yoff General Hospital. Strengthening primary health care through promotion and prevention is an alternative, especially for poor populations.

Keywords: PAH, NCD, Grand Yoff General Hospital

\section{Introduction}

"Potentially avoidable hospitalizations" (PAHs) or sensitive hospitalizations to primary care (SHPC) are hospitalizations that are necessary at the time of hospital admission but could have been prevented by appropriate primary health care (Freund et al., 2012; Billings, 1990; Weissman et al., 1992).

The PAHs are mainly attributable to chronic non-communicable diseases, which are a global public health priority (Moodie et al., 2013; Cesare et al., 2013; Bonita et al., 2013). Worldwide, the burden of NCDs has increased rapidly (Atun et al., 2013; Murray et al., 2012). It accounted for $60 \%$ of the 56 million deaths and $47 \%$ of global morbidity in 2001 (WHO, 2011). NCDs are increasing, especially in low and middle-income countries (Cesare et al., 2013; WHO, 2011; Lozano et al., 2012).

In several countries of the Organization for Economic Cooperation and Development (OECD), potentially 
avoidable hospitalizations are the subject of much research initiated in the 1990s in the USA. These studies emphasized on the multidimensional nature of PAHs, highlighting links between PAHs and characteristics of patients, health staff, health system and environment (Freund et al., 2012; Billings, 1990; Weissman et al., 1992; Pappas et al., 1997; Ricketts et al., 2001).

According to WHO global report in 2010, NCDs are the leading cause of death worldwide. Out of 36 million deaths, $48 \%$ are due to cardiovascular diseases, $21 \%$ to cancer, $12 \%$ to chronic respiratory diseases and $3 \%$ to diabetes (WHO, 2011; Kankeu et al., 2013). Approximately 80\% of cases occurred in low and middle-income countries (WHO, 2011; Kankeu et al., 2013; Abegunde et al., 2007).

In Africa, NCDs are increasing (Dalal et al., 2011; Conner et al., 2007) and coexist with infectious diseases in several regions (Atun et al., 2013; Dalal et al., 2011; Mathers et al., 2006; Lopez et al., 2006). In Senegal, fragmented studies have shown the high frequency of NCDs in some groups (Seck et al., 2013; Ndiaye et al., 2016; Mbaye et al., 2011; Sow et al., 2014).

NCDs are a heavy financial burden for affected households, and the poorest are most affected when they seek care. The cost of care discourages many people with NCDs from seeking the care they need (Kankeu et al., 2013; Abegunde et al., 2007; Strong et al., 2005). Health insurance coverage is still limited and medical expenses are borne largely by families (Kankeu et al., 2013; Bloom et al., 2011; WHO, 2012). WHO estimates that the impact of NCD-related deaths could be reduced through interventions focused on the improvement of provision of health services, screening and adequate treatment (Moodie et al., 2013; WHO, 2012; Murray et al., 2014).

In this context, this study aimed to evaluate potentially avoidable hospitalizations at Grand Yoff General Hospital. More specifically, it was to estimate the extent of PAHs in Grand Yoff General Hospital, to determine the geographical accessibility of the hospital according to hospitalized patients and to analyze the average medical expenses for PAHs management at Grand Yoff General Hospital.

\section{Methodology}

This was a cross-sectional descriptive study of the potentially avoidable hospitalizations noted at Grand Yoff General Hospital.

\subsection{Population and Inclusion Criteria}

The study population consisted of all the patients hospitalized at Grand Yoff General Hospital during the period from April 01 to August 31, 2015. Targeted diseases met following characteristics:

- Diabetes: The diagnosis of diabetes is based on fasting blood glucose greater than or equal to $1.26 \mathrm{~g} / 1$ twice or random blood glucose greater than or equal to $2.00 \mathrm{~g} / 1$ in case of evocative symptoms or on anti-diabetic treatment (Oladapo et al., 2010).

- High blood pressure was defined as a systolic pressure greater than or equal to $140 \mathrm{~mm}$ of mercury or diastolic pressure greater than or equal to $90 \mathrm{~mm}$ of mercury or on antihypertensive therapy (Oladapo et al., 2010).

- Chronic pulmonary disease was defined as chronic broncho-pulmonary disorder.

- Chronic kidney disease was defined independently of its cause by the presence of renal disorder markers or a drop in glomerular filtration rate (GFR) below $60 \mathrm{ml} / \mathrm{min} / 1.73 \mathrm{~m}^{2}$ for more than 3 months (National Kidney Foundation, 2002).

- Cerebral vascular accident (or stroke) is a condition that occurs as a result of a problem in the arteries of the brain. Two types of stroke are distinguished:

○ ischemic stroke, marked by a motor deficit

- Hemorrhagic stroke, characterized rather by an alteration of consciousness

Was included in the study any patient aged more than one year, hospitalized at Grand Yoff General Hospital for a period at least equal to 4 hours.

Non-inclusion referred to patients who met the inclusion criteria but hospitalized at surgery (general surgery, ENT, ophthalmology), maternity or neonatology, or those who refused to participate in the study or were unable to answer the questions.

This was a comprehensive sampling that included all inpatients who met the selection criteria.

Following the development of the data collection tool, several individual interviews were held with the staff of the Human Resources Directorate and the Head of Nursing to put in place administrative arrangements that could guarantee a legal framework and ensure a proper conduct of information gathering. 
The introduction of the person responsible for the survey to the senior nurses of the various visited departments facilitated collaboration with the staff of the structure for better access to eligible patients for the survey. Nursing staff had helped to identify patients who met the eligibility criteria of the survey. Some information was collected from accompanying persons whenever the condition of the patient eligible for the survey did not enable him / her to continue to answer the questions correctly.

A questionnaire developed from SPHINX software was used as a collection tool. It included:

- A first part dealing with the identification of the patient, his socio-demographic characteristics,

- A second part related to hospitalization: reasons, length of stay, outcome, hospitalization expenses,

- A third part concerning the information on the disease: including before the hospitalization (Knowledge of the signs of severity, Knowledge of the means of prevention) and during the hospitalization (knowledge of the signs of severity, the means of prevention and the behavior to be adopted).

\subsection{Data Collection}

The direct administration of the questionnaire to each eligible patient was adopted as the main approach. This method has helped to clarify and involve the respondent in the study project, but also to reduce the risks of information bias.

The information was collected by the investigator. In order to carry out the collection, patients who were eligible for the survey and who were in the structure were interviewed by direct interview. Furthermore, in the emergency and cardiology departments, accompanying persons and relatives of the patient participated in the survey by helping their sick relative (inpatient) to answer the questions.

\subsection{Data Entry and Analysis}

The collected information was entered using Sphinx software and then processed with SPSS software. The qualitative variables were presented in percentages and the quantitative variables by using the mean with standard deviations or the median with the 25 th and 75 th quartiles. The frequency comparison was carried out using chi ${ }^{2}$ test and the comparison of averages by the variance analysis.

\subsection{Ethical Aspects}

The investigation was authorized by the director of the hospital following the advice of the technical medical board. Participation was free and voluntary for patients meeting the selection criteria. All information regarding the patient's identity was confidential. An informed consent form was signed by each patient or his / her accompanying person at the beginning of the interview.

\section{Results}

At the end of data collection, 110 patients meeting the eligibility criteria were interviewed.

\subsection{Characteristics of Participants}

The average age of patients was $57 \pm 17.49$ years with a median (IQR25-IQR75) of 60 years (49-71). Also16.36\% of patients interviewed were between the ages of 1 and 39 years; $29.09 \%$ between 40 and 59 years. More than half of the participants $(54.55 \%)$ belonged to the age group of $60-87$ years. (See Table 1 )

The sex ratio was 0.96 . The married accounted for $68.18 \%$ of the participants, widowed $21.82 \%$ and singles $10 \%$. (See table I).

Regarding education, $36.36 \%$ of surveyed patients were uneducated and $23.64 \%$ reached primary school. Nearly 3 out of 10 participants reached high school and only $8.20 \%$ reached college. Regarding occupational activity, almost $43.64 \%$ of participants were housewives and $22.73 \%$ retired. Only $8.18 \%$ of the interviewees had a paid job (civil servants $6.40 \%$ and private employees $1.8 \%$ ). At last, $5.45 \%$ of surveyed patients were students or pupils. (See Table 1)

Regarding monthly incomes, $86.36 \%$ earned less than 100 USD and only $3.64 \%$ earned 200 USD or more. (See Table 1) 
Table 1. Socio-demographic and Economic Characteristics of Participants $(n=110)$

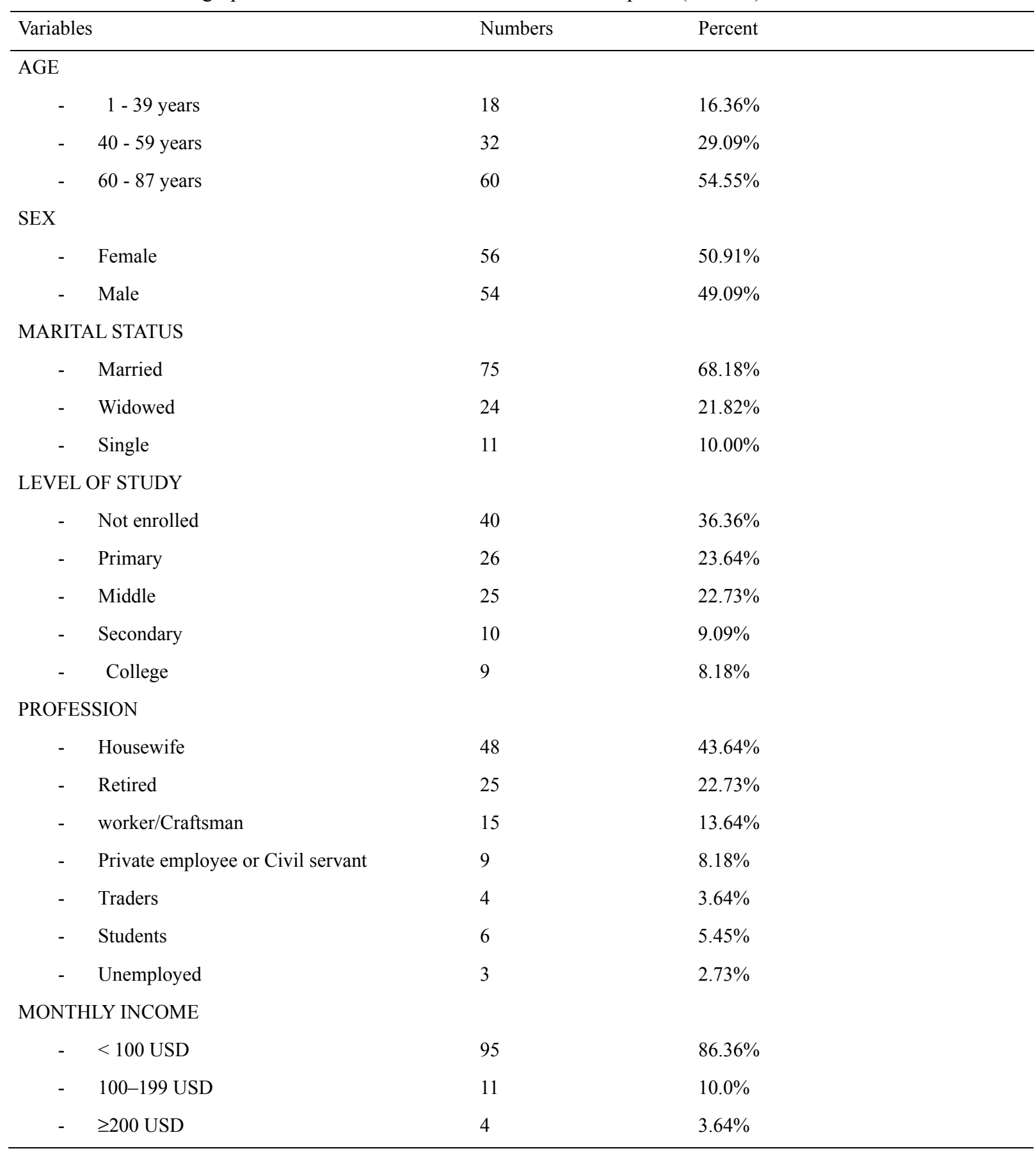

\subsection{According to the Reason for Hospitalization}

During the study, 739 hospitalizations were recorded at the targeted services. Thus, the proportion of PAHs was estimated at $14.88 \%$ in this study (Table II).

Pulmonary disease was the leading cause of avoidable hospitalizations at Grand Yoff General Hospital at 4.74\%, respectively followed by diabetes $(4.06 \%)$ stroke $(3.65 \%)$, chronic kidney disease $(1.35 \%)$ and high blood pressure $(1.08 \%)$ (Table 2). 
Table 2. Distribution of potentially avoidable hospitalizations by pathology at Grand Yoff General Hospital

\begin{tabular}{lll}
\hline Reason hospitalization & Number & Percent \\
\hline Chronic pulmonary disease & 35 & 4.74 \\
Diabetes & 30 & 4.06 \\
Stroke & 27 & 3.65 \\
Chronic kidney disease & 10 & 1.35 \\
High blood pressure & 8 & 1.08 \\
TOTAL & 110 & 14.88 \\
\hline
\end{tabular}

\subsection{Depending on the Average Length of Stay}

The average length of stay of PAHs was 8 days. Hospitalizations ranged from 1 to 45 days. The standard deviation was 7.88. The median was 5 days and the mode was equal to 3 days. (Table 3 )

Approximately 4 out of 10 patients had a length of stay less than 5 days and almost 3 out of 10 patients had a length of stay between 5 and 9 days; 3 out of 10 patients had a length of stay greater than or equal to 10 days (Table 3 ).

Table 3. Average length of stay of patients study on PAHs at HOGGY $(n=110)$

\begin{tabular}{lll}
\hline Length of stay & Number & Pourcent \\
\hline Less than 5 days & 45 & $40.90 \%$ \\
from 5 to 9 days & 31 & $28.20 \%$ \\
from 10 to 14 days & 19 & $17.30 \%$ \\
15 and higher & 15 & $13.60 \%$ \\
\hline
\end{tabular}

\subsection{Recrudescence of PAHs}

Table IV shows that 2 out of 10 patients surveyed were at least at their second hospitalization in the last 12 months. This proportion was $42 \%$ among participants hospitalized for pulmonary disease and $23 \%$ among those hospitalized for diabetes. Regarding stroke, $4 \%$ were concerned.

Table 4. Recrudescence of PAHs at Grand Yoff General Hospital by cause over 12 months

\begin{tabular}{lll}
\hline \multirow{2}{*}{ Cause of hospitalization } & Frequency of hospitalizations \\
\cline { 2 - 3 } & 1 st time & 2 times and more \\
\hline Chronic pulmorary disease & $58 \%$ & $42 \%$ \\
Diabetes & $77 \%$ & $23 \%$ \\
Hypertension & $73 \%$ & $27 \%$ \\
Stroke & $96 \%$ & $4 \%$ \\
Chronic kidney disease & $100 \%$ & $0 \%$ \\
TOTAL & $78 \%$ & $22 \%$ \\
\hline
\end{tabular}

The comparison of the level of awareness of the disease severity before hospitalization and at the end of the stay (Table 5) shows a statistically significant improvement, from $37.3 \%$ to $71.8 \%(\mathrm{p}<0.01)$.

Also, the level of information about the means of disease prevention and its complications changed significantly with $32.7 \%$ before hospitalization and $64.5 \%$ at the end of the stay (Table 5). 
Table 5. Evolution of the knowledge level of PAHs before and at the end of the stay

\begin{tabular}{lll}
\hline Knowledge & Before admission & End of stay \\
\hline Awareness of disease severity & $37.3 \%$ & $71.8 \%$ \\
Information about disease prevention means and/or its complications & $32.7 \%$ & $64.5 \%$ \\
\hline
\end{tabular}

\section{Discussion}

This study demonstrated a relatively high frequency of potentially avoidable hospitalizations at Grand Yoff General Hospital (14.88\%), with subjects over the age of 60 being more represented (54.5\%), and the frequency of PAHs correlated to that reported in a hospital in northern Senegal (54\%), but subjects aged 40-59 were as represented as those aged 60 or older (Ndiaye et al., 2017).

On the other hand, Giraud and collaborators (Giraud et al., 2016) observed a frequency of $6.4 \%$ in a study carried out in Poitou-Charentes, slightly higher for men, and three times higher in the aged group over 65 years compared to the aged group 20-64 years. In Ile de France, a frequency of PAHs of 5.7\% was mentioned (Freund et al., 2012).

Another study shows that $60 \%$ of hospitalizations in Canada are due to chronic diseases; $2 / 3$ of emergency hospitalizations are complications of chronic diseases; $80 \%$ of visits to the general practitioner are related to a chronic disease and in most cases, these pathologies are potentially preventable (Cesare et al., 2013). 60-80\% of health spending is the result of chronic diseases (Atun et al., 2013).

This study shows that PAHs are concentrated in subjects aged 60 or older, with low or no education, men and women, housewives and retirees, with a monthly income of less than 100 USD. But Ndiaye et al had demonstrated that PAHs mainly affected the 40 or more years old, artisans or housewives, more women than men (Ndiaye et al., 2017). However, as in this study, married people and none or poorly educated subjects with a monthly income less than 100 USD were more represented.

Considering the reasons for hospitalization in this study, pulmonary disease was the leading cause of avoidable hospitalizations $(4.74 \%)$, respectively followed by diabetes $(4.06 \%)$, stroke $(3.65 \%)$, chronic kidney disease $(1.35 \%)$ and high blood pressure (1.08\%). But according to the study of PAHs in Saint Louis, diabetes was the leading cause of PAHs (22.1\%) respectively followed by chronic kidney disease (12\%), malignant high blood pressure $(10.9 \%)$, stroke $(6.4 \%)$ and pulmonary disease $(2.6 \%)$. However, the average length of stay found in the studies were very close, 8 days at Grand Yoff General Hospital and 6.68 days at Saint-Louis Regional Hospital (Ndiaye et al., 2017). In France, an average length of stay of 8.7 days was observed in Poitou-Charentes (Giraud et al., 2016).

This study showed a double improvement of the level of awareness of disease severity and that of the information related to disease prevention means and/or its complications. A similar evolution was mentioned in Saint-Louis (Ndiaye et al., 2017).

\section{Conclusion}

The emergence of non-communicable diseases is a real threat to people, especially in developing countries. This study showed that diabetes, hypertension, pulmonary disease, stroke (ischemic, hemorrhagic) and chronic kidney disease are frequent reasons for hospitalization in Senegal. People aged 60 and over are the most affected. The economic cost of their medical care may likely constitute a major obstacle to the political will of an emerging Senegal. Fortunately, there are simple and effective solutions focusing on health promotion and primary prevention, with a better primary health care organization.

\section{Authors' Contributions}

NDIAYE Abdoul Aziz: design, data collection, statistical analysis and manuscript review. Other authors: design and manuscript review. All the authors have read and approved the final version of the manuscript.

\section{Acknowledgments}

The authors would like to acknowledge the participants and the Hospital Direction for their support.

\section{Competing Interests Statement}

The authors declare no competing interests.

\section{References}

Abegunde, D. O., Mathers, C. D., Adam, T., \& Ortegon, M. (2007). The burden and costs of chronic diseases in 
low-income and middle-income countries. $\quad$ Lancet, $\quad 370, \quad 1929-38$. https://doi.org/10.1016/S0140-6736(07)61696-1

Atun, R., Jaffar, S., Nishtar, S., Knaul, F. M., Barreto, M. L., Nyirenda, M. et al. (2013). Improving responsiveness of health systems to non-communicable diseases. Lancet, 381, 690-97. https://doi.org/10.1016/S0140-6736(13)60063-X

Billings, J. (1990). Consideration of the use of small area analysis as a tool to evaluate barriers to access. In Health resources and services administration, consensus on small area analysis. DHHS Pub. No. HRSA-PE, 91-1[A], Washington, DC: US Department of Health and Human Services.

Bloom, D. E., Cafiero, E. T., Jané-Llopis, E., Abrahams-Gessel, S., Bloom, L. R., Fathima, S. et al. (2011). The Global Economic Burden of Non-communicable Diseases. Geneva: World Economic Forum. Retrieved from http://www.hsph.harvard.edu/pgda/working.htm

Bonita, R., Magnusson, R., Bovet, P., Zhao, D., Malta, D. C., Geneau, R. et al. (2013). Country actions to meet UN commitments on non-communicable diseases: a stepwise approach. Lancet, 381, 575-84. https://doi.org/10.1016/S0140-6736(12)61993-X

Cesare, M. D., Khang, Y. H., Asaria, P., Blakely, T., Cowan, M. J., Farzadfar, F. et al. (2013). Inequalities in non-communicable diseases and effective responses. Lancet, 381, 585-97. https://doi.org/10.1016/S0140-6736(12)61851-0

Conner, M. D., Walker, R., Modi, G., \& Warlow, C. P. (2007). Burden of stroke in black population in sub-saharan Africa. Lancet Neurol.,6(3), 269-78. https://doi.org/10.1016/S1474-4422(07)70002-9

Dalal, S., Beunza, J. J., Volmink, J., Adebamowo, C., Bajunirwe, F., Njelekela, M. et al. (2011). Non-communicable diseases in sub-Saharan Africa: what we know now. Int. J. Epidemiol., 40(4), 885-901. https://doi.org/10.1093/ije/dyr050

Freund, R. J., Tonnellier, F., Philippon, J. F. (2012). Potentially avoidable hospitalisation in Île-de-France and accessibility to cares. Journal of Epidemiology and Public Health, 60, S134. Retrieved from https://www.researchgate.net/publication/270638065.

Giraud, J., Pubert, M., \& Garnaud, A.-T. (2016). Les hospitalisations potentiellement évitables en Poitou-Charentes. ORS Poitou-Charentes. Mars 2016. 6p. Retrieved from www.ors-poitou-charentes.org

Kankeu, H. T., Saksena, P., Xu, K., \& Evans, D. B. (2013). The financial burden from non-communicable diseases in low and middle-income countries: a literature review. Health research policy and systems, 11, 31. https://doi.org/10.1186/1478-4505-11-31

Lopez, A. D., Mathers, C. D., Ezzati, M., Jamison, D. T., \& Murray, C. J. (2006). Global and regional burden of disease and risk factors, 2001: systematic analysis of population health data. Lancet, 367, 1747-57. https://doi.org/10.1016/S0140-6736(06)68770-9

Lozano, R., Naghavi, M., Foreman, K., Lim, S., Shibuya, K., Aboyans, V. et al. (2012). Global mortality from 235 causes of death for 20 age groups in 1990 and 2010: a systematic analysis for the Global Burden of Disease Study 2010. Lancet, 380, 2095-128. https://doi.org/10.1016/S0140-6736(12)61728-0

Mathers, C. D., \& Loncar, D. (2006). Projections of global mortality and burden of disease from 2002 to 2030. Plos Med., 3, 442. https://doi.org/10.1371/journal.pmed.0030442

Mbaye, M. N., Niang, K., Sarr, A., Mbaye, A., Diedhiou, D., Ndao, M. D. et al. (2011). Aspects épidémiologiques du diabète au Sénégal : résultats d'une enquête sur les facteurs de risque cardiovasculairedans la ville de Saint-Louis. Médecine des maladies métaboliques, 5(6), 659-64.

Moodie, R., Stuckler, D., Monteiro, C., Sheron, N., Neal, B., Thamarangsi, T. et al. (2013). Profits and pandemics: prevention of harmful effects of tobacco, alcohol, and ultra-processed food and drink industries. Lancet, 381, 670-79. https://doi.org/10.1016/S0140-6736(12)62089-3

Murray, C. J. L., Vos, T., Lozano, R., Naghavi, M., Flaxman, A. D., Michaud, C. et al. (2012). Disability-adjusted life-years (DALYs) for 291 diseases and injuries in 21 regions, 1990-2010: a systematic analysis for the Global Burden of Disease Study 2010. Lancet, $2197-223$. https://doi.org/10.1016/S0140-6736(12)61689-4

Murray, C. J., Ortblad, K. F., Guinovart, C., Lim, S. S., Wolock, T. M., Robert, D. A. et al. (2014). Global, regional, and national incidence and mortality for HIV, tuberculosis, and malaria during 1990-2013: a systematic 
analysis for the Global Burden of Disease Study 2013. Lancet, 384 (9947), 1005-70. https://doi.org/10.4236/health.2016.814151

National Kidney Foundation. K/DOQI Clinical Practice Guidelines for Chronic Kidney Disease. Evaluation, Classification and Stratification. Am J Kidney Dis, 39(2 Suppl), S1-S266.

Ndiaye, A. A., Tall, A. B., Gueye, B., Fall, I. S., Seck, S. M., Mbodji, A. B. et al. (2016). A cross-sectional survey on non-communicable diseases and risk factors in the Senegalese army. Health, 8, 1529-1541. https://doi.org/10.4236/health.2016.814151

Ndiaye, A. A., Bakhoum, M., Tall, A. B., Ngom-Gueye, N. F., Seck, S. M., Gueye, B. et al. (2017). Assessment of potentially preventable hospitalizations in the regional hospital of Saint-Louis. Pan African Medical Journal, 27(125). https://doi.org/10.11604/pamj.2017.27.125.10360

Oladapo, O. O., Falase, A. O., Salako, L., Sodiq, O., Shoyinka, K., \& Adedapo, K. (2017). A prevalence of cardiometabolic risk factors among a Yoruba South-western Nigerian population: a populationbased survey. Cardiovasc J Afr., 21(1), 26-31.

Pappas, G., Hadden, W. C., Kozak, I. J., \& Fisher, G. F. (1997), Potentially avoidable hospitalizations: Inequalities in rates between US socioeconomic groups. American Journal of public health, 87, 811-816. https://doi.org/10.2105/AJPH.87.5.811

Ricketts, T. C., Randolph, R., Howard, H. A., Pathman, D., \& Carey, T. (2001). Hospitalization rates as indicators of access to primary care. Health \& Place, 7(2001) 7-38. https://doi.org/10.1016/S1353-8292(00)00035-6

Seck, S. M., Gueye, S., Tamba, K., \& Ba, I. (2010). Prevalence of chronic cardiovascular and metabolic diseases in Senegalese workers: a cross-sectional study 2010. Prev. Chronic Dis., 10, 110339. https://doi.org/10.5888/pcd10.110339

Sow, P. G., Ka, O., Goume, M., Tall, A. B., \& Ndiaye, A. A. The Prevalence of Arterial Hypertension and associated factors in the Senegalese population in Dakar. American J Pharm Health Res., 2(4).

Strong, K. L., Mathers, C. D., Leeder, S., \& Beaglehole, R. (2005). Preventing chronic diseases: how many lives can we save? Lancet, 366, 1578-82. https://doi.org/10.1016/S0140-6736(05)67341-2

Weissman, J. S., Gatsonis, C., \& Epstein, A. M. (1992). Rates of avoidable hospitalization by insurance status in Massachusetts and Maryland. JAMA, 268, 2388-2394. https://doi.org/10.1001/jama.1992.03490170060026

World Health Organization. (2011). Global status on non-communicable diseases 2010. Geneva: WHO, 2011.

World Health Organization. (2012). World Health Statistics 2012. Geneva: World Health Organization; 2012.

\section{Copyrights}

Copyright for this article is retained by the author(s), with first publication rights granted to the journal.

This is an open-access article distributed under the terms and conditions of the Creative Commons Attribution license (http://creativecommons.org/licenses/by/4.0/). 